OPEN ACCESS

Edited by:

Moussa Antoine Chalah, Hôpitaux Universitaires Henri

Mondor, France

Reviewed by:

James W. Grau,

Texas A\&M University, United States Tomofumi Yamaguchi, Yamagata Prefectural University of Health Sciences, Japan Vincenzo Di Lazzaro, Campus Bio-Medico University, Italy

*Correspondence: Aiko K. Thompson thompsai@musc.edu

Specialty section This article was submitted to Multiple Sclerosis and

Neuroimmunology, a section of the journa

Frontiers in Neurology

Received: 31 January 2020 Accepted: 15 May 2020

Published: 15 July 2020

Citation:

Thompson AK and Sinkjær T (2020)

Can Operant Conditioning of EMG-Evoked Responses Help to Target Corticospinal Plasticity for Improving Motor Function in People

With Multiple Sclerosis?

Front. Neurol. 11:552.

doi: 10.3389/fneur.2020.00552

\section{Can Operant Conditioning of EMG-Evoked Responses Help to Target Corticospinal Plasticity for Improving Motor Function in People With Multiple Sclerosis?}

\author{
Aiko K. Thompson ${ }^{1 *}$ and Thomas Sinkjær ${ }^{2,3}$ \\ ${ }^{1}$ Department of Health Sciences and Research, College of Health Professions, Medical University of South Carolina, \\ Charleston, SC, United States, ${ }^{2}$ Department of Health Science and Technology, Aalborg University, Aalborg, Denmark, \\ ${ }^{3}$ Lundbeck Foundation, Copenhagen, Denmark
}

Corticospinal pathway and its function are essential in motor control and motor rehabilitation. Multiple sclerosis (MS) causes damage to the brain and descending connections, and often diminishes corticospinal function. In people with MS, neural plasticity is available, although it does not necessarily remain stable over the course of disease progress. Thus, inducing plasticity to the corticospinal pathway so as to improve its function may lead to motor control improvements, which impact one's mobility, health, and wellness. In order to harness plasticity in people with MS, over the past two decades, non-invasive brain stimulation techniques have been examined for addressing common symptoms, such as cognitive deficits, fatigue, and spasticity. While these methods appear promising, when it comes to motor rehabilitation, just inducing plasticity or having a capacity for it does not guarantee generation of better motor functions. Targeting plasticity to a key pathway, such as the corticospinal pathway, could change what limits one's motor control and improve function. One of such neural training methods is operant conditioning of the motor-evoked potential that aims to train the behavior of the corticospinal-motoneuron pathway. Through up-conditioning training, the person learns to produce the rewarded neuronal behavior/state of increased corticospinal excitability, and through iterative training, the rewarded behavior/state becomes one's habitual, daily motor behavior. This minireview introduces operant conditioning approach for people with MS. Guiding beneficial CNS plasticity on top of continuous disease progress may help to prolong the duration of maintained motor function and quality of life in people living with MS.

Keywords: operant conditioning, motor-evoked potential, corticospinal excitability, foot drop, plasticity

\section{INTRODUCTION}

Over the past 15 years, the awareness of the importance of physical rehabilitation and exercise has been steadily growing in the field of multiple sclerosis (MS)-related research (1-3). This trend should continue, with ongoing development and testing of disease-modifying drugs (4), which will lead to prolonging disease stability and creating greater opportunities for reducing motor 
impairments, improving mobility, and improving quality of life in people with MS, as pointed out by Ploughman (3). Although underlying mechanisms may not be fully understood (5), mounting evidence indicates positive effects of exercise on physical fitness, balance and mobility, cognitive function, participation, and other outcomes $(1,6)$. A challenge is that a person with MS may not be able to appreciate the greatness of exercise, when reduced movement efficiency and impaired mobility make it difficult for him/her to be engaged in physical activity. Without changing what is available to execute essential daily motor function such as gait, and without changing what is limiting one's function, movement dysfunction would continue to limit mobility and quality of life in people with MS. While disease progress continuously alters one's physiology, it is essential to guide the central nervous system (CNS) plasticity that can help to prolong the duration of maintained motor function and quality of life in people living with MS.

In this brief review, we will discuss the corticospinal plasticity in people with MS and introduce operant conditioning approach as a method to target plasticity in the corticospinal pathway for improving motor function in people with MS.

\section{CNS PLASTICITY IN PEOPLE WITH MS}

MS is a chronic inflammatory, autoimmune disease of the CNS. In persons with MS, neurological deficits are commonly attributed to inflammatory demyelination in the CNS and damage to the gray matter in cortical and subcortical structures, with lesion patterns, locations, volumes, and their rates of changes differing among subtypes of MS (7-10). In addition to accumulating structural damage, the process of inflammation itself affects synaptic transmission and plasticity (11). Elevation in the level of inflammatory cytokines not only changes glutamatergic and GABAergic transmissions, which lead to synaptic hyperexcitability and excitotoxicity, but also affects synaptic plasticity (11-14), which is essential for clinical and functional recovery. Thus, from damage to the brain and the descending pathways and from alteration in synaptic plasticity, disruption of corticospinal function is a hard-to-avoid problem in people with MS (15-17).

Transcranial magnetic stimulation (TMS), its motor-evoked potential (MEP), and their associated measures, such as shortand long-interval cortical inhibition (SICI and LICI), shortinterval cortical facilitation (SICF), and intracortical facilitation (ICF), are useful tools for investigating cortical and corticospinal plasticity (18-22). They are also useful in detecting and predicting the progression of disability and recovery $(15,16,23-$ 27). For instance, small MEPs with long latencies, high motor thresholds, and prolonged cortical silent periods tend to correlate with the Expanded Disability Status Scale (EDSS) scores (15$17,28-30$ ). Silent period (SP) after MEP, known to reflect cortical inhibition at least partly $(31-37)$, is reduced in the relapsing or progressive phases of MS $(38,39)$, whereas the SP is prolonged in the remitting phase (38). In the stable phase of relapsingremitting MS individuals, SICI and ICF could be similar to those of the control group (17). A common observation is that cortical inhibition is reduced during the relapsing or progressive phase, whereas the inhibition is clearly present during the stable or remitting phase (11); the phase or state of disease appears to be reflected in the measured cortical inhibition. In addition, how these measures respond to plasticity-inducing neuromodulation can suggest the availability of plasticity at the time of assessment and help to predict recovery from relapse $(11-13,23,40)$.

The availability of synaptic plasticity, also known as "plasticity reserve" (11), can be measured in persons with MS by applying plasticity-inducing neuromodulation techniques, such as repetitive TMS (rTMS) at high (e.g., $20 \mathrm{~Hz}$ ) or low (e.g., $1 \mathrm{~Hz}$ ) frequency, rTMS with intermittent or continuous theta burst stimulation patterns (iTBS and cTBS) $(11,13,14,41,42)$, paired associative stimulation (PAS) with TMS, and peripheral nerve stimulation (PNS) $(12,23,43,44)$. They can be used to assess long-term potentiation (with high-frequency rTMS and iTBS), long-term depression (with low-frequency rTMS and (TBS), and spike-timing-dependent Hebbian-type plasticity (with PAS) $(11,13,42)$. For example, in individuals with primary progressive MS, neither iTBS nor cTBS exert the expected plasticity effects; in individuals in the relapsing phase of MS, iTBS produces expected LTP effects, but cTBS fails to produce expected LTD effects (42). This plasticity reserve may be an essential mechanism of clinical symptom and disability progression in MS; when plasticity reserve is exhausted and synaptic plasticity is unavailable, surviving neurons would not be able to compensate for neuronal loss (11).

Importantly, while people with MS can display plasticity $(43,45-48)$, there is no guarantee that their plasticity adaptive to progressive neuronal damage is beneficial; it may exaggerate or lessen clinical symptoms (42). Thus, to guide the plasticity in beneficial directions, a neurobehavioral training should be incorporated into MS rehabilitation. For improving impaired motor function in people with MS, it would be critically important to induce and maintain beneficial plasticity in the corticospinal pathway, as its function is the foundation of voluntary and involuntary motor behaviors.

\section{NEUROMODULATION FOR REHABILITATION IN PEOPLE WITH MS}

There are a wide variety of neurorehabilitation interventions currently available or being tested for individuals with CNS disorders, including MS (https://clinicaltrials.gov). Many of those expect to induce cortical and/or subcortical plasticity and may improve sensorimotor function [e.g., (49-52)]. Of different neuromodulation approaches, there have been growing interests in non-invasive brain stimulation (NIBS); in particular, rTMS and transcranial direct current stimulation (tDCS) have been increasingly utilized for treating various MS symptoms (41, 53-59). Other neuromodulation methods, such as deep brain stimulation and spinal cord stimulation, have been reviewed in (60). As effects and mechanisms of rTMS and tDCS have been thoroughly covered in recent reviews $(54-56,58)$, these methods will not be further discussed in this minireview. However, it is worth reiterating that studies of LTP or LTD-inducing 
rTMS (e.g., iTBS, low-frequency rTMS) and tDCS that affects polarization of the stimulated cortical network have shown some promising results; common MS symptoms, such as fatigue, cognitive functions, pain, and spasticity, can be alleviated by these methods (40, 41, 53, 54, 56-58, 61, 62).

When applying NIBS for improving impaired motor function, consideration on how to guide the stimulation-induced plasticity is critically important. Because NIBS-induced plasticity is rather widespread and not pathway specific, without an additional strategy to shape such plasticity into functionally beneficial changes, many changes at many different sites could compensate for each other, toward maintaining the state of neural network at net change of zero [i.e., homeostatic plasticity (63-69)]. Thus, pairing two interventions, e.g., iTBS + exercise (70), could be a logical NIBS application strategy for motor rehabilitation. Task-specific PNS, such as FES for foot drop (71-73), with which functional movement and phase-specific PNS occur concurrently, uniquely emulates a neuromodulation combination strategy, increases MEP amplitude, and improves motor function in people with MS and other neuromuscular disorders $(49,74)$.

Another class of neuromodulation methods include PAS $(23,43,75-79)$ and operant conditioning of muscle [electromyographic (EMG)]-evoked potentials (80-82), which target plasticity in a specific pathway. Detailed mechanisms of PAS approaches have been discussed in $(75,76,78,83,84)$. Briefly, with PAS protocols that induces spike-timing-dependent plasticity (76-78), synaptic transmission can be potentiated or depressed depending on the relative timing between the presynaptic and postsynaptic spiking $(77,85,86)$, and repeated application of TMS-PNS PAS can potentiate corticospinalmotoneuronal transmission and excitability in people with MS $(43,45)$. A similar PAS concept can also be applied to cortical neurons $(79,87,88)$. Therapeutic potency of PAS in people with MS is yet to be determined.

\section{OPERANT CONDITIONING OF EMG-EVOKED POTENTIALS}

Operant conditioning is a method for modifying a behavior based on the consequence of that behavior (89). Usually, when a person acquires a new behavior through operant conditioning, s/he does not need to discover the operant contingency through trial and error. However, when this approach is applied to a behavior of a neural pathway (e.g., a reflex), an individual must go through a trial-and-error discovery phase, as s/he would not have prior knowledge on how to control volitionally a behavior or the excitability of that specific pathway. Thus, with operant conditioning of an EMG-evoked potential that reflects the behavior and/or excitability of a certain neural pathway, a subject learns to produce a neuronal behavior that is rewarded through trial and error, similarly between humans and animals (89). Through repetition, the rewarded behavior can become a habitual behavior (90). With operant conditioning of an EMGevoked potential, such as a reflex and an MEP, a subject is rewarded only for increasing or decreasing a target pathway's excitability $(81,82)$. Thus, over time, it changes the pathway that produces that response (82).

By changing the transmission of a key pathway with a directional aim (up/down), operant conditioning of an EMGevoked potential seeks to improve the targeted pathway's function and enable more effective movements in which the targeted pathway contributes $(91,92)$. An emerging theory is that changing a key pathway leads to a cascade of wider beneficial changes in the activity of other spinal and supraspinal pathways $(81,93)$, impacting motor function recovery.

Much of the physiological and theoretical knowledge of operant conditioning approach is based on a large number of reflex conditioning studies $(68,82,94)$. The most essential includes the following. An operantly conditioned reflex behavior rests on a hierarchy of plasticity from the brain to the spinal cord $(68,82,95,96)$. The reward contingency produces plasticity in the brain that induces and maintains the spinal cord plasticity that is directly responsible for the conditioned reflex behavior $(68,82$, 94). Among the major descending pathways, the corticospinal tract is the only pathway essential for conditioning-induced plasticity (97). Thus, when the corticospinal tract and its plasticity are preserved at least partially, the targeted change can be induced through conditioning (98), which then changes how that reflex pathway functions in complex motion such as locomotion (80, $92,99)$. These provide the foundation for currently emerging clinical applications of MEP operant conditioning.

\section{OPERANT CONDITIONING OF THE MOTOR-EVOKED POTENTIALS}

As in reflex operant conditioning $(68,81,82,100-102)$, operantly up-conditioning the MEP can increase the corticospinal excitability for the targeted muscle in people $(91,103)$. In the first 100-1,000 up-conditioning trials, a person learns through trial and error how to increase MEP size, and MEP size gradually increases over the subsequent conditioning sessions (Figure 1). Motivation is critical in operant conditioning $(89,90,106,107)$; the person must value the positive feedback that $\mathrm{s} /$ he receives from producing a larger MEP. Our studies suggest that in individuals with CNS disorders, who take the conditioning trials more seriously than those without CNS injury, MEP size is highly likely to increase, and their MEP increase can persist at least a few months after conditioning ends $(103,104)$.

Two key factors underline the therapeutic potency of MEP conditioning. First, it targets plasticity to the corticospinal pathway that produces an MEP in the targeted muscle. The protocol prohibits change in the background EMG activity; the individual is rewarded only for increasing the target muscle's MEP (i.e., for increasing corticospinal excitability for the target muscle). This pathway specificity differentiates MEP conditioning from EMG biofeedback training (108-112) or muscle strength training (113-119), both of which are not tailored for modulating or controlling the excitability or behavior a specific pathway. While practice is essential in improving motor performance, movement practice alone could let an individual easily default to relying on what is readily 
A

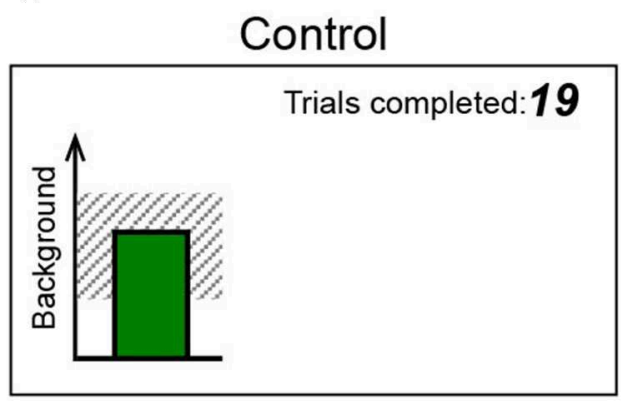

B
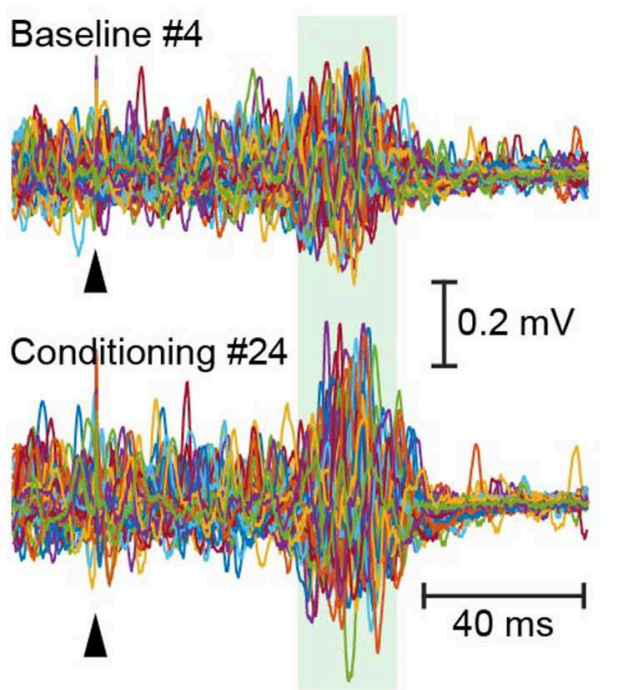

D
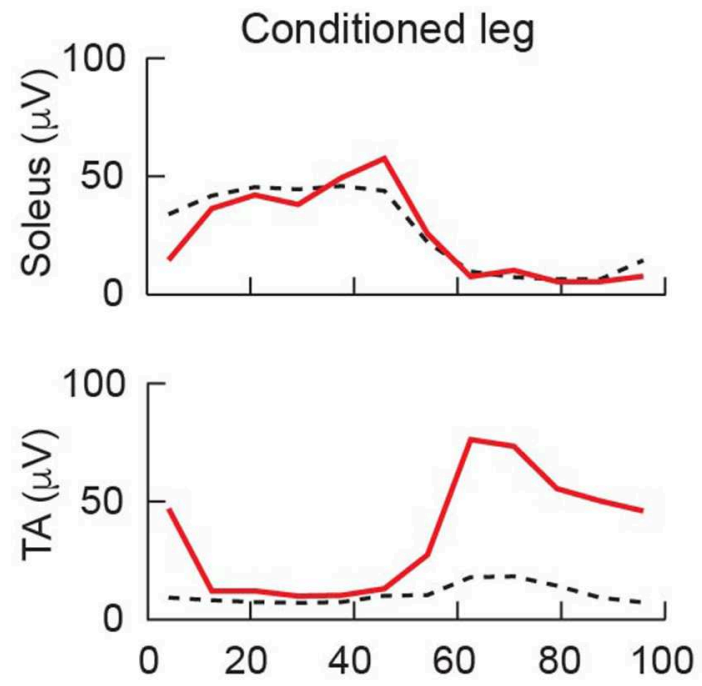

$\%$ step cycle
Up-conditioning (success)

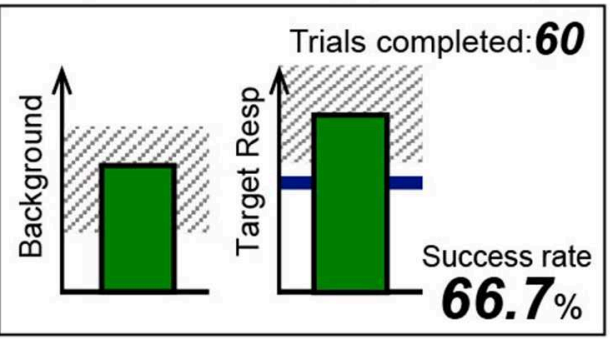

C

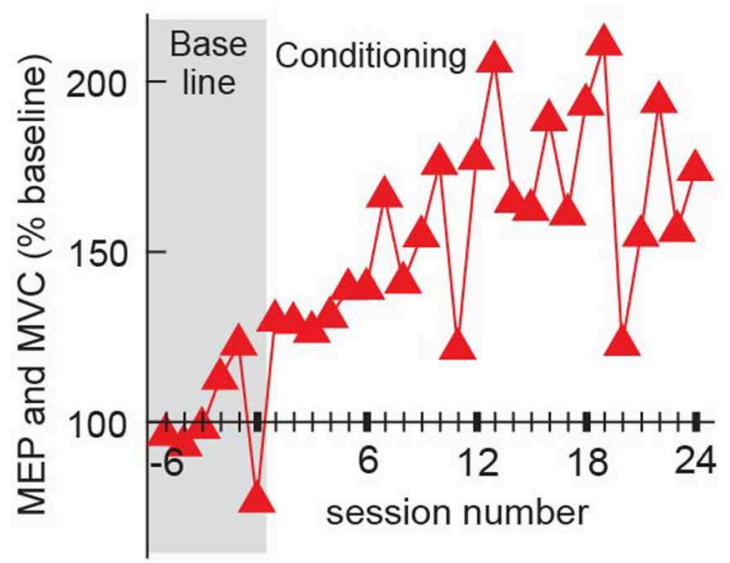

FIGURE 1 | Operant conditioning of the tibialis anterior (TA) motor-evoked potential (MEP) in individuals with multiple sclerosis (MS) [modified from (104)]. (A) Visual feedback screens for MEP control and MEP operant conditioning trials. In all trials, the number of the current trial within its block is displayed, and the background 
FIGURE 1 | electromyographic (EMG) panel shows the correct range (shaded) and the current value (green vertical bar, updated every $200 \mathrm{~ms}$ ). If TA EMG activity stays in the correct range for at least $2 \mathrm{~s}$ and at least $5.5 \mathrm{~s}$ has passed since the last trial, an MEP is elicited. In control trials (left), the MEP panel is not shown. In conditioning trials (right), the shading in the MEP panel indicates the rewarded MEP range for up-conditioning. The dark horizontal line is the average MEP size of the baseline sessions, and the vertical bar is the MEP size, calculated in the MEP interval of that specific individual [e.g., 45-70 ms after transcranial magnetic stimulation (TMS)], for the most recent trial. The vertical bar appears $200 \mathrm{~ms}$ after TMS. If that MEP size reaches into the shaded area, the bar is green, and the trial is a success. If it falls below the shaded area, the bar is red, and the trial is a not a success. The running success rate for the current block is shown at the bottom. (B) Examples of TA MEP in a 56-year-old woman with MS (Expanded Disability Status Scale $4.0^{\star}$ at baseline). Peristimulus EMG sweeps from the fourth baseline session (top) and the 24th conditioning session (bottom). For each part, 75 sweeps are superimposed. A green shaded band indicates the time window for her MEP size calculation. Arrowheads indicate the time of TMS. (C) Mean MEP size (i.e., the mean of 225 control MEP trials in baseline sessions or 225 conditioned MEP trials in conditioning sessions) in 6 baseline and 24 conditioning sessions that occurred at a rate of 3 sessions/week. Over the course of conditioning, her MEP size increased progressively; the final MEP size was $175 \%$ of the baseline value. (D) Rectified locomotor EMG activity in soleus and TA bilaterally before (dashed black) and after (solid red) conditioning. The step cycle, from foot contact to the end of swing phase, is divided into 12 equal bins. After TA MEP up-conditioning, swing phase TA burst increased in the conditioned leg, which helped this individual regain ankle dorsiflexion and eliminated foot drop. The swing phase burst was also increased in the contralateral TA. All panels have been adapted from (104) with permission. *EDSS 4.0 (105): Fully ambulatory without aid, self-sufficient, up and about some $12 \mathrm{~h}$ a day despite relatively severe disability consisting of one FS grade 4 (others 0 or 1), or combination of lesser grades exceeding limits of previous steps; able to walk without aid or rest some $500 \mathrm{~m}$.

available (e.g., trying to rely on the hip flexors, instead of improving corticospinal drive to the impaired ankle dorsiflexors), leaving a key pathway unchanged. Because MEP up-conditioning increases the excitability of the corticospinal pathway for the target muscle, it affects motor skills, such as locomotion, to which the pathway contributes. Thus, with the ankle dorsiflexor tibialis anterior (TA) MEP up-conditioning (Figure 1), locomotion can be improved in people suffering from foot drop (weak ankle dorsiflexion) $(91,104)$.

Second, by improving the function of a key pathway, corticospinal pathway, MEP conditioning can trigger further beneficial changes in the activity of other CNS pathways $(80,81$, $93,120)$, changing what is possible/available in one's recovery path. By targeting the weakened corticospinal drive to the TA and ameliorating the locomotor impediment of foot drop, TA MEP conditioning can enable more effective execution of locomotion; this would then induce wider beneficial plasticity. Increased corticospinal drive to the conditioned TA (49) can explain increases in TA MEP and TA burst amplitude during the swing phase of locomotion observed in people with MS and SCI (91, 104) but cannot explain widespread bilateral improvements in locomotor EMG activity $(91,104)$ (Figure 1). These wider effects of MEP conditioning are similar to those of the soleus H-reflex down-conditioning, with which proximal and distal leg muscles' locomotor EMG improved bilaterally in people with SCI (92). How an operant-conditioning acquired new skill of changing a specific pathway's excitability would trigger a widespread adaptive plasticity in many spinal/supraspinal pathways has been addressed in a theory of system function known as the negotiated equilibrium model $(68,93)$.

\section{EFFECTS OF MEP CONDITIONING AND CORTICOSPINAL PLASTICITY IN PEOPLE WITH MS}

Among people with foot drop due to MS or SCI, locomotor TA activity improved and walking speed increased while MEP increased $(91,103,104)$. Conditioning-induced MEP increase was often accompanied by systematic decrease in SP duration $(103,104)$. SP is known to reflect cortical inhibition at least partly (31-37), and different neural circuits underlie MEP and SP (121-123). If MEP up-conditioning simply increased the general excitability of the cortex, both MEP and SP would have increased [e.g., (124)]. This was not the case. Instead, there were some selective effects on excitatory and inhibitory neurons in the cortex $(125,126)$. Since reduction in intracortical inhibition occurs through modulation of GABAergic inhibitory interneurons $(127-131)$, it is highly likely that GABAergic inhibitory mechanisms are involved in conditioning-induced SP changes. SPs are often prolonged in people with stable or secondary progressive MS $(28,29,132)$, which likely reflects altered $G_{A B A}-$ mediated intracortical inhibition $(33,131,133,134)$. Despite an altered state of cortical inhibition in preconditioning, MEP up-conditioning could reduce SP in individuals with stable MS (104). Further investigation is clearly needed to understand the mechanisms and effects of MEP up-conditioning on cortical inhibition in MS.

\section{OPERANT CONDITIONING OF SPINAL REFLEXES}

In addition to MEP conditioning protocols, several reflex conditioning protocols are currently being developed. To date, two protocols have been systematically tested in people with or without CNS damage: the soleus short-latency stretch reflex (known as M1 response) conditioning, using mechanical joint perturbation (135), and the soleus H-reflex conditioning, which uses electrical stimulation of the tibial nerve $(92,99,102$, 136). With both stretch and H-reflex conditioning protocols, the person learns to increase or decrease the target reflex size over 24-30 conditioning sessions. The protocols are designed to induce sustaining changes in descending influence over the reflex pathway, which in turn, produce targeted plasticity in that pathway (101). Because these protocols can change the transmission of targeted pathways, they can be designed to address the specific functional deficits of an individual. For example, in people with spastic hyperreflexia due to incomplete SCI, down-conditioning of the soleus $\mathrm{H}$ reflex pathway, whose hyperactivity impaired locomotion, could improve their locomotion $(80,92)$. Down-conditioning of the 
stretch or H-reflex might also improve spasticity and spastic movement disorders in people with MS (137). It should also be possible to condition other important pathways, such as pathways of spinal reciprocal and presynaptic inhibition (138140), for further improving their motor functions.

\section{OPERANT CONDITIONING IN MS: CHALLENGES AND POSSIBILITIES}

Up until now, the majority of evoked potential operant conditioning studies have been done in SCI $(68,80,82$, 92, 99, 141-145), and its investigation in MS is still in an early stage. Unique challenges in the MS population that do not necessarily apply to the SCI population include impaired cognitive function, fatigue, and ongoing and/or recurring inflammation $(14,56,59,146)$. Since operant conditioning is a behavioral learning approach $(81,82,89)$, impairments in learning, memory, and attention that are frequently found in MS may affect the effectiveness of this approach in people with MS. The fact that recurring inflammation influences synaptic plasticity and plasticity reserve $(11,13)$, which are physiological mechanism of learning, memory, and function recovery, could well interfere with induction and maintenance of conditioninginduced beneficial plasticity. Furthermore, extents of these challenges could vary among MS subtypes and across different individuals $(11,17,38,42)$. Clearly, more studies are needed to determine the applicability of operant conditioning approach in people with MS, and an investigation needs to include persons with all MS subtypes. Long-term follow-up should also be part of such investigations, although often unpredictable disease progress may mask or reduce the induction of plasticity and function improvements temporally or permanently $(23,44,49$, 74). Over 3.5 years of follow-up with a woman with secondary progressive MS supports a possibility of long-term maintenance of corticospinal transmission and function improvements with MEP operant conditioning (104).

A possible strategy to overcome the above-mentioned MS-related challenges is coadministration of conditioning training with NIBS or pharmacological treatment. Reflex or MEP conditioning that aims to change behaviors of the targeted pathway is fundamentally different from rTMS and tDCS, or pharmacological treatments, such as baclofen $(147,148)$. Because the mechanisms of action differ so

\section{REFERENCES}

1. Motl RW, Sandroff BM, Kwakkel G, Dalgas U, Feinstein A, Heesen C, et al. Exercise in patients with multiple sclerosis. Lancet Neurol. (2017) 16:848-56. doi: 10.1016/S1474-4422(17)30281-8

2. Motl RW, Goldman MD, Benedict RH. Walking impairment in patients with multiple sclerosis: exercise training as a treatment option. Neuropsychiatr Dis Treat. (2010) 6:767-74. doi: 10.2147/NDT.S10480

3. Ploughman M. A new era of multiple sclerosis rehabilitation: lessons from stroke. Lancet Neurol. (2017) 16:768-9. doi: 10.1016/S1474-4422(17)30301-0

4. Gerardi C, Bertele V, Rossi S, Garattini S, Banzi R. Preapproval and postapproval evidence on drugs for multiple sclerosis. Neurology. (2018) 90:964-73. doi: 10.1212/WNL.0000000000005561 vastly from each other, with careful consideration of dosing schedules and individual or combined effects, it may be possible to enhance functional outcomes by coadministering a conditioning protocol with another intervention. Drugs such as dalfampridine and D-aspartate (149-153) may further enhance the corticospinal plasticity and transmission improvement produced by MEP conditioning.

\section{CONCLUSION}

A growing number of neurophysiological studies indicate the importance of neuroplasticity and its management for neurorehabilitation in people with MS $(11,13,54,56-60$, 154). While the benefit of exercise in health and wellness has become recognized $(1,6)$, investigation on how to improve impaired motor function and mobility, which can limit one's ability to exercise, has been left behind (3). Applying neural training methods, such as operant conditioning of EMG-evoked potentials, to guide beneficial plasticity in the corticospinal or other important CNS pathways may minimize the factors that limit function improvement in people with MS. As CNS plasticity remains available over many years of disease progress (43, 46, 47), guiding it appropriately to gain function improvements on top of changing physiology may help to prolong the duration of maintained motor function and quality of life in people with MS.

\section{AUTHOR CONTRIBUTIONS}

AT drafted, edited, and revised the manuscript. TS edited and revised the manuscript. Both authors read and approved the final version submitted for publication.

\section{FUNDING}

This work was supported in part by Sawmill owner Jeppe Juhl's and wife Ovita Juhl's Memorial Legate and Spar Nord Fonden of Denmark, the US National Institute of Neurological Disorders and Stroke (R01NS114279), the US National Institute of Biomedical Imaging and Bioengineering (P41EB018783), the US National Institute of General Medical Sciences [GM104941, Institutional Development Award (IDeA) to Binder-MacLeod], and the Doscher Neurorehabilitation Research Program.

5. Negaresh R, Motl RW, Mokhtarzade M, Dalgas U, Patel D, Shamsi MM, et al. Effects of exercise training on cytokines and adipokines in multiple sclerosis: a systematic review. Mult Scler Relat Disord. (2018) 24:91-100. doi: 10.1016/j.msard.2018.06.008

6. Motl RW, Pilutti LA. The benefits of exercise training in multiple sclerosis. Nat Rev Neurol. (2012) 8:487-97. doi: 10.1038/nrneurol.2012.136

7. Klaver R, de Vries HE, Schenk GJ, Geurts JJ. Grey matter damage in multiple sclerosis: a pathology perspective. Prion. (2013) 7:66-75. doi: 10.4161/pri.23499

8. Nijeholt GJ, van Walderveen MA, Castelijns JA, van Waesberghe JH, Polman $\mathrm{C}$, Scheltens $\mathrm{P}$, et al. Brain and spinal cord abnormalities in multiple sclerosis. Correlation between MRI parameters, clinical subtypes and symptoms. Brain. (1998) 121(Pt 4):687-97. doi: 10.1093/brain/121.4.687 
9. Calabrese M, Magliozzi R, Ciccarelli O, Geurts JJ, Reynolds R, Martin R. Exploring the origins of grey matter damage in multiple sclerosis. Nat Rev Neurosci. (2015) 16:147-58. doi: 10.1038/nrn3900

10. Datta G, Colasanti A, Rabiner EA, Gunn RN, Malik O, Ciccarelli O, et al. Neuroinflammation and its relationship to changes in brain volume and white matter lesions in multiple sclerosis. Brain. (2017) 140:2927-38. doi: 10.1093/brain/awx228

11. Stampanoni Bassi M, Mori F, Buttari F, Marfia GA, Sancesario A, Centonze D, et al. Neurophysiology of synaptic functioning in multiple sclerosis. Clin Neurophysiol. (2017) 128:1148-57. doi: 10.1016/j.clinph.2017.04.006

12. Stampanoni Bassi M, Iezzi E, Mori F, Simonelli I, Gilio L, Buttari F, et al. Interleukin- 6 disrupts synaptic plasticity and impairs tissue damage compensation in multiple sclerosis. Neurorehabil Neural Repair. (2019) 33:825-35. doi: 10.1177/1545968319868713

13. Nistico R, Mori F, Feligioni M, Nicoletti F, Centonze D. Synaptic plasticity in multiple sclerosis and in experimental autoimmune encephalomyelitis. Philos Trans R Soc Lond B Biol Sci. (2014) 369:20130162. doi: 10.1098/rstb.2013.0162

14. Mori F, Rossi S, Sancesario G, Codeca C, Mataluni G, Monteleone F, et al. Cognitive and cortical plasticity deficits correlate with altered amyloid-beta CSF levels in multiple sclerosis. Neuropsychopharmacology. (2011) 36:55968. doi: $10.1038 / n p p .2010 .187$

15. Kale N, Agaoglu J, Onder G, Tanik O. Correlation between disability and transcranial magnetic stimulation abnormalities in patients with multiple sclerosis. J Clin Neurosci. (2009) 16:1439-42. doi: 10.1016/j.jocn.2009.03.009

16. Gagliardo A, Galli F, Grippo A, Amantini A, Martinelli C, Amato MP, et al. Motor evoked potentials in multiple sclerosis patients without walking limitation: amplitude vs conduction time abnormalities. J Neurol. (2007) 254:220-7. doi: 10.1007/s00415-006-0334-5

17. Conte A, Lenzi D, Frasca V, Gilio F, Giacomelli E, Gabriele M, et al. Intracortical excitability in patients with relapsing-remitting and secondary progressive multiple sclerosis. J Neurol. (2009) 256:933-8. doi: 10.1007/s00415-009-5047-0

18. Hallett M. Transcranial magnetic stimulation: a primer. Neuron. (2007) 55:187-99. doi: 10.1016/j.neuron.2007.06.026

19. Pascual-Leone A, Davey NJ, Rothwell J, Wassermann EM, Puri BK. Handbook of Transcranial Magnetic Stimulation. London: Arnold, a member of the Hodder Headline Group (2002).

20. Pascual-Leone A, Walsh V, Rothwell J. Transcranial magnetic stimulation in cognitive neuroscience-virtual lesion, chronometry, functional connectivity. Curr Opin Neurobiol. (2000) 10:232-7. doi: 10.1016/S0959-4388(00)00081-7

21. Hallett M. Transcranial magnetic stimulation and the human brain. Nature. (2000) 406:147-50. doi: 10.1038/35018000

22. Cohen LG, Ziemann U, Chen R, Classen J, Hallett M, Gerloff C, et al. Studies of neuroplasticity with transcranial magnetic stimulation. J Clin Neurophysiol. (1998) 15:305-24. doi: 10.1097/00004691-199807000-00003

23. Mori F, Kusayanagi H, Nicoletti CG, Weiss S, Marciani MG, Centonze D. Cortical plasticity predicts recovery from relapse in multiple sclerosis. Mult Scler. (2013) 20:451-7. doi: 10.1177/1352458513512541

24. Schlaeger R, D'Souza M, Schindler C, Grize L, Dellas S, Radue EW, et al. Prediction of long-term disability in multiple sclerosis. Mult Scler. (2012) 18:31-8. doi: 10.1177/1352458511416836

25. Schmierer K, Irlbacher K, Grosse P, Roricht S, Meyer BU. Correlates of disability in multiple sclerosis detected by transcranial magnetic stimulation. Neurology. (2002) 59:1218-24. doi: 10.1212/WNL.59.8.1218

26. Fuhr P, Kappos L. Evoked potentials for evaluation of multiple sclerosis. Clin Neurophysiol. (2001) 112:2185-9. doi: 10.1016/S1388-2457(01)00687-3

27. Fuhr P, Borggrefe-Chappuis A, Schindler C, Kappos L. Visual and motor evoked potentials in the course of multiple sclerosis. Brain. (2001) 124(Pt 11):2162-8. doi: 10.1093/brain/124.11.2162

28. Neva JL, Lakhani B, Brown KE, Wadden KP, Mang CS, Ledwell NH, et al. Multiple measures of corticospinal excitability are associated with clinical features of multiple sclerosis. Behav Brain Res. (2016) 297:187-95. doi: 10.1016/j.bbr.2015.10.015

29. Chaves AR, Kelly LP, Moore CS, Stefanelli M, Ploughman M. Prolonged cortical silent period is related to poor fitness and fatigue, but not tumor necrosis factor, in multiple sclerosis. Clin Neurophysiol. (2019) 130:474-83. doi: 10.1016/j.clinph.2018.12.015
30. Mori F, Kusayanagi H, Monteleone F, Moscatelli A, Nicoletti CG, Bernardi $G$, et al. Short interval intracortical facilitation correlates with the degree of disability in multiple sclerosis. Brain Stimul. (2013) 6:67-71. doi: 10.1016/j.brs.2012.02.001

31. Fuhr P, Agostino R, Hallett M. Spinal motor neuron excitability during the silent period after cortical stimulation. Electroencephalogr Clin Neurophysiol. (1991) 81:257-62. doi: 10.1016/0168-5597(91)90011-L

32. Ziemann U, Netz J, Szelenyi A, Homberg V. Spinal and supraspinal mechanisms contribute to the silent period in the contracting soleus muscle after transcranial magnetic stimulation of human motor cortex. Neurosci Lett. (1993) 156:167-71. doi: 10.1016/0304-3940(93)90464-V

33. Chen R, Lozano AM, Ashby P. Mechanism of the silent period following transcranial magnetic stimulation. Evidence from epidural recordings. Exp Brain Res. (1999) 128:539-42. doi: 10.1007/s002210050878

34. Bertasi V, Bertolasi L, Frasson E, Priori A. The excitability of human cortical inhibitory circuits responsible for the muscle silent period after transcranial brain stimulation. Exp Brain Res. (2000) 132:384-9. doi: $10.1007 / s 002210000352$

35. Shimizu T, Hino T, Komori T, Hirai S. Loss of the muscle silent period evoked by transcranial magnetic stimulation of the motor cortex in patients with cervical cord lesions. Neurosci Lett. (2000) 286:199-202. doi: 10.1016/S0304-3940(00)01125-3

36. Wu T, Sommer M, Tergau F, Paulus W. Modification of the silent period by double transcranial magnetic stimulation. Clin Neurophysiol. (2000) 111:1868-72. doi: 10.1016/S1388-2457(00)00426-0

37. Schnitzler A, Benecke R. The silent period after transcranial magnetic stimulation is of exclusive cortical origin: evidence from isolated cortical ischemic lesions in man. Neurosci Lett. (1994) 180:41-5. doi: 10.1016/0304-3940(94)90909-1

38. Caramia MD, Palmieri MG, Desiato MT, Boffa L, Galizia P, Rossini PM, et al. Brain excitability changes in the relapsing and remitting phases of multiple sclerosis: a study with transcranial magnetic stimulation. Clin Neurophysiol. (2004) 115:956-65. doi: 10.1016/j.clinph.2003.11.024

39. Nantes JC, Zhong J, Holmes SA, Narayanan S, Lapierre Y, Koski L. Cortical damage and disability in multiple sclerosis: relation to intracortical inhibition and facilitation. Brain Stimul. (2016) 9:566-73. doi: 10.1016/j.brs.2016.01.003

40. Mori F, Codeca C, Kusayanagi H, Monteleone F, Boffa L, Rimano A, et al. Effects of intermittent theta burst stimulation on spasticity in patients with multiple sclerosis. Eur J Neurol. (2010) 17:295-300. doi: $10.1111 / j .1468-1331.2009 .02806 . x$

41. Korzhova J, Bakulin I, Sinitsyn D, Poydasheva A, Suponeva N, Zakharova $\mathrm{M}$, et al. High-frequency repetitive transcranial magnetic stimulation and intermittent theta-burst stimulation for spasticity management in secondary progressive multiple sclerosis. Eur J Neurol. (2019) 26:680-e44. doi: $10.1111 /$ ene.13877

42. Weiss S, Mori F, Rossi S, Centonze D. Disability in multiple sclerosis: when synaptic long-term potentiation fails. Neurosci Biobehav Rev. (2014) 43:88-99. doi: 10.1016/j.neubiorev.2014.03.023

43. Zeller D, aufm Kampe K, Biller A, Stefan K, Gentner R, Schutz A, et al. Rapid-onset central motor plasticity in multiple sclerosis. Neurology. (2010) 74:728-35. doi: 10.1212/WNL.0b013e3181d31dcf

44. Wirsching I, Buttmann M, Odorfer T, Volkmann J, Classen J, Zeller D. Altered motor plasticity in an acute relapse of multiple sclerosis. Eur $J$ Neurosci. (2018) 47:251-7. doi: 10.1111/ejn.13818

45. Stein RB, Everaert DG, Roy FD, Chong S, Soleimani M. Facilitation of corticospinal connections in able-bodied people and people with central nervous system disorders using eight interventions. J Clin Neurophysiol. (2013) 30:66-78. doi: 10.1097/WNP.0b013e31827ed6bd

46. Tomassini V, Johansen-Berg H, Jbabdi S, Wise RG, Pozzilli C, Palace $J$, et al. Relating brain damage to brain plasticity in patients with multiple sclerosis. Neurorehabil Neural Repair. (2012) 26:581-93. doi: $10.1177 / 1545968311433208$

47. Tomassini V, Matthews PM, Thompson AJ, Fuglo D, Geurts JJ, JohansenBerg H, et al. Neuroplasticity and functional recovery in multiple sclerosis. Nat Rev Neurol. (2012) 8:635-46. doi: 10.1038/nrneurol.2012.179

48. Schubert M, Wohlfarth K, Rollnik JD, Dengler R. Walking and fatigue in multiple sclerosis: the role of the 
corticospinal system. Muscle Nerve. (1998) 21:1068-70. doi: 10.1002/(sici)1097-4598(199808)21:8<1068::aid-mus12>3.0.co;2-q

49. Everaert DG, Thompson AK, Chong SL, Stein RB. Does functional electrical stimulation for foot drop strengthen corticospinal connections? Neurorehabil Neural Repair. (2010) 24:168-77. doi: $10.1177 / 1545968309349939$

50. Stein RB, Everaert D, Chong SL, Thompson AK. Using FES for foot drop strengthens cortico-spinal connections. In: 12th Annual Conference of teh International FES Society. Philadelphia, PA (2007).

51. Lo AC, Triche EW. Improving gait in multiple sclerosis using robot-assisted, body weight supported treadmill training. Neurorehabil Neural Repair. (2008) 22:661-71. doi: 10.1177/1545968308318473

52. Giesser B, Beres-Jones J, Budovitch A, Herlihy E, Harkema S. Locomotor training using body weight support on a treadmill improves mobility in persons with multiple sclerosis: a pilot study. Mult Scler. (2007) 13:224-31. doi: $10.1177 / 1352458506070663$

53. Charvet LE, Dobbs B, Shaw MT, Bikson M, Datta A, Krupp LB. Remotely supervised transcranial direct current stimulation for the treatment of fatigue in multiple sclerosis: Results from a randomized, sham-controlled trial. Mult Scler. (2018) 24:1760-69. doi: 10.1177/1352458517732842

54. Leocani L, Chieffo R, Gentile A, Centonze D. Beyond rehabilitation in MS: insights from non-invasive brain stimulation. Mult Scler. (2019) 25:1363-71. doi: $10.1177 / 1352458519865734$

55. Ayache SS, Chalah MA. Transcranial direct current stimulation: a glimmer of hope for multiple sclerosis fatigue? J Clin Neurosci. (2018) 55:10-12. doi: 10.1016/j.jocn.2018.06.002

56. Ayache SS, Chalah MA. The place of transcranial direct current stimulation in the management of multiple sclerosis-related symptoms. Neurodegener Dis Manag. (2018) 8:411-22. doi: 10.2217/nmt-2018-0028

57. Palm U, Ayache SS, Padberg F, Lefaucheur JP. Non-invasive brain stimulation therapy in multiple sclerosis: a review of tDCS, rTMS and ECT results. Brain Stimul. (2014) 7:849-54. doi: 10.1016/j.brs.2014.09.014

58. Iodice R, Manganelli F, Dubbioso R. The therapeutic use of non-invasive brain stimulation in multiple sclerosis - a review. Restor Neurol Neurosci. (2017) 35:497-509. doi: 10.3233/RNN-170735

59. Nasios G, Bakirtzis C, Messinis L. Cognitive impairment and brain reorganization in MS: underlying mechanisms and the role of neurorehabilitation. Front Neurol. (2020) 11:147. doi: 10.3389/fneur.2020.00147

60. Abboud H, Hill E, Siddiqui J, Serra A, Walter B. Neuromodulation in multiple sclerosis. Mult Scler. (2017) 23:1663-76. doi: $10.1177 / 1352458517736150$

61. Mori F, Codeca C, Kusayanagi H, Monteleone F, Buttari F, Fiore S, et al. Effects of anodal transcranial direct current stimulation on chronic neuropathic pain in patients with multiple sclerosis. J Pain. (2010) 11:436-42. doi: 10.1016/j.jpain.2009.08.011

62. Mori F, Nicoletti CG, Kusayanagi H, Foti C, Restivo DA, Marciani MG, et al. Transcranial direct current stimulation ameliorates tactile sensory deficit in multiple sclerosis. Brain Stimul. (2013) 6:654-9. doi: 10.1016/j.brs.2012.10.003

63. Turrigiano GG. Homeostatic plasticity in neuronal networks: the more things change, the more they stay the same. Trends Neurosci. (1999) 22:2217. doi: 10.1016/S0166-2236(98)01341-1

64. Ziemann U, Ilic TV, Pauli C, Meintzschel F, Ruge D. Learning modifies subsequent induction of long-term potentiation-like and long-term depression-like plasticity in human motor cortex. J Neurosci. (2004) 24:166672. doi: 10.1523/JNEUROSCI.5016-03.2004

65. Jung P, Ziemann U. Homeostatic and nonhomeostatic modulation of learning in human motor cortex. I Neurosci. (2009) 29:5597-604. doi: 10.1523/JNEUROSCI.0222-09.2009

66. Potter-Nerger M, Fischer S, Mastroeni C, Groppa S, Deuschl G, Volkmann J, et al. Inducing homeostatic-like plasticity in human motor cortex through converging corticocortical inputs. J Neurophysiol. (2009) 102:3180-90. doi: 10.1152/jn.91046.2008

67. Muller JF, Orekhov Y, Liu Y, Ziemann U. Homeostatic plasticity in human motor cortex demonstrated by two consecutive sessions of paired associative stimulation. Eur J Neurosci. (2007) 25:3461-8. doi: $10.1111 /$ j.1460-9568.2007.05603.x
68. Wolpaw JR. What can the spinal cord teach us about learning and memory? Neuroscientist. (2010) 16:532-49. doi: 10.1177/1073858410368314

69. Karabanov A, Ziemann U, Hamada M, George MS, Quartarone A, Classen J, et al. Consensus paper: probing homeostatic plasticity of human cortex with non-invasive transcranial brain stimulation. Brain Stimul. (2015) 8:9931006. doi: 10.1016/j.brs.2015.06.017

70. Mori F, Ljoka C, Magni E, Codeca C, Kusayanagi H, Monteleone F, et al. Transcranial magnetic stimulation primes the effects of exercise therapy in multiple sclerosis. J Neurol. (2011) 258:1281-7. doi: 10.1007/s00415-011-5924-1

71. Khaslavskaia S, Sinkjaer T. Motor cortex excitability following repetitive electrical stimulation of the common peroneal nerve depends on the voluntary drive. Exp Brain Res. (2005) 162:497-502. doi: $10.1007 / \mathrm{s} 00221-004-2153-1$

72. Khaslavskaia S, Ladouceur M, Sinkjaer T. Increase in tibialis anterior motor cortex excitability following repetitive electrical stimulation of the common peroneal nerve. Exp Brain Res. (2002) 145:309-15. doi: 10.1007/s00221-002-1094-9

73. Kido Thompson A, Stein RB. Short-term effects of functional electrical stimulation on motor-evoked potentials in ankle flexor and extensor muscles. Exp Brain Res. (2004) 159:491-500. doi: 10.1007/s00221-004-1972-4

74. Stein RB, Everaert DG, Thompson AK, Chong SL, Whittaker M, Robertson $\mathrm{J}$, et al. Long-term therapeutic and orthotic effects of a foot drop stimulator on walking performance in progressive and nonprogressive neurological disorders. Neurorehabil Neural Repair. (2010) 24:152-67. doi: $10.1177 / 1545968309347681$

75. Christiansen L, Perez MA. Targeted-Plasticity in the corticospinal tract after human spinal cord injury. Neurotherapeutics. (2018) 15:618-27. doi: 10.1007/s13311-018-0639-y

76. Bunday KL, Perez MA. Motor recovery after spinal cord injury enhanced by strengthening corticospinal synaptic transmission. Curr Biol. (2012) 22:2355-61. doi: 10.1016/j.cub.2012.10.046

77. Taylor JL, Martin PG. Voluntary motor output is altered by spike-timingdependent changes in the human corticospinal pathway. J Neurosci. (2009) 29:11708-16. doi: 10.1523/JNEUROSCI.2217-09.2009

78. Suppa A, Quartarone A, Siebner H, Chen R, Di Lazzaro V, Del Giudice $\mathrm{P}$, et al. The associative brain at work: evidence from paired associative stimulation studies in humans. Clin Neurophysiol. (2017) 128:2140-64. doi: 10.1016/j.clinph.2017.08.003

79. Mrachacz-Kersting N, Voigt M, Stevenson AJT, Aliakbaryhosseinabadi S, Jiang N, Dremstrup K, et al. The effect of type of afferent feedback timed with motor imagery on the induction of cortical plasticity. Brain Res. (2017) 1674:91-100. doi: 10.1016/j.brainres.2017.08.025

80. Thompson AK, Wolpaw JR. Restoring walking after spinal cord injury: operant conditioning of spinal reflexes can help. Neuroscientist. (2015) 21:203-15. doi: 10.1177/1073858414527541

81. Thompson AK, Wolpaw JR. Targeted neuroplasticity for rehabilitation. Prog Brain Res. (2015) 218:157-72. doi: 10.1016/bs.pbr.2015.02.002

82. Thompson AK, Wolpaw JR. Operant conditioning of spinal reflexes: from basic science to clinical therapy. Front Integr Neurosci. (2014) 8:25. doi: $10.3389 /$ fnint. 2014.00025

83. Carson RG, Kennedy NC. Modulation of human corticospinal excitability by paired associative stimulation. Front Hum Neurosci. (2013) 7:823. doi: $10.3389 /$ fnhum.2013.00823

84. Palmer JA, Halter A, Gray W, Wolf SL, Borich MR. Modulatory effects of motor state during paired associative stimulation on motor cortex excitability and motor skill learning. Front Hum Neurosci. (2019) 13:8. doi: 10.3389/fnhum.2019.00008

85. Usrey WM, Reppas JB, Reid RC. Paired-spike interactions and synaptic efficacy of retinal inputs to the thalamus. Nature. (1998) 395:384-7. doi: $10.1038 / 26487$

86. Bi GQ, Poo MM. Synaptic modifications in cultured hippocampal neurons: dependence on spike timing, synaptic strength, and postsynaptic cell type. $J$ Neurosci. (1998) 18:10464-72. doi: 10.1523/JNEUROSCI.18-24-10464.1998

87. Mrachacz-Kersting N, Kristensen SR, Niazi IK, Farina D. Precise temporal association between cortical potentials evoked by motor imagination and afference induces cortical plasticity. J Physiol. (2012) 590:1669-82. doi: 10.1113/jphysiol.2011.222851 
88. Mrachacz-Kersting N, Stevenson AJT, Jorgensen HRM, Severinsen KE, Aliakbaryhosseinabadi S, Jiang N, et al. Brain state-dependent stimulation boosts functional recovery following stroke. Ann Neurol. (2019) 85:84-95. doi: 10.1002/ana.25375

89. McSweeney FK, Murphy ES. The Wiley Blackwell Handbook of Operant and Classical Conditioning. Chichester, UK: John Wiley and Sons, Incorporated. (2014). doi: 10.1002/9781118468135

90. Schultz W. Neuronal reward and decision signals: from theories to data. Physiol Rev. (2015) 95:853-951. doi: 10.1152/physrev.00023.2014

91. Thompson AK, Fiorenza G, Smyth L, Favale B, Brangaccio J, Sniffen J. Operant conditioning of the motor-evoked potential and locomotion in people with and without chronic incomplete spinal cord injury. $J$ Neurophysiol. (2019) 121:853-66. doi: 10.1152/jn.00557.2018

92. Thompson AK, Pomerantz FR, Wolpaw JR. Operant conditioning of a spinal reflex can improve locomotion after spinal cord injury in humans. J Neurosci. (2013) 33:2365-75. doi: 10.1523/JNEUROSCI.3968-12.2013

93. Wolpaw JR. The negotiated equilibrium model of spinal cord function. $J$ Physiol. (2018) 596:3469-91. doi: 10.1113/JP275532

94. Thompson AK, Wolpaw JR. The simplest motor skill: mechanisms and applications of reflex operant conditioning. Exerc Sport Sci Rev. (2014) 42:82-90. doi: 10.1249/JES.0000000000000010

95. Chen XY, Wang Y, Chen Y, Chen L, Wolpaw JR. The inferior olive is essential for long-term maintenance of a simple motor skill. J Neurophysiol. (2016) 116:1946-55. doi: 10.1152/jn.00085.2016

96. Wolpaw JR, Chen XY. Operant conditioning of reflexes. In: Squire LR, editor. Encyclopedia of Neuroscience. Oxford: Academic Press (2009). p. 225-233. doi: 10.1016/B978-008045046-9.01347-4

97. Chen XY, Wolpaw JR. Probable corticospinal tract control of spinal cord plasticity in the rat. J Neurophysiol. (2002) 87:645-52. doi: 10.1152/jn.00391.2001

98. Chen XY, Wolpaw JR, Jakeman LB, Stokes BT. Operant conditioning of H-reflex in spinal cord-injured rats. J Neurotrauma. (1996) 13:755-66. doi: 10.1089/neu.1996.13.755

99. Thompson AK, Wolpaw JR. H-reflex conditioning during locomotion in people with spinal cord injury. J Physiol. (2019) doi: 10.1113/JP278173. [Epub ahead of print].

100. Wolpaw JR. Spinal cord plasticity in acquisition and maintenance of motor skills. Acta Physiol. (2007) 189:155-69. doi: 10.1111/j.1748-1716.2006.01656.x

101. Wolpaw JR. The complex structure of a simple memory. Trends Neurosci. (1997) 20:588-94. doi: 10.1016/S0166-2236(97)01133-8

102. Thompson AK, Chen XY, Wolpaw JR. Acquisition of a simple motor skill: task-dependent adaptation plus long-term change in the human soleus H-reflex. J Neurosci. (2009) 29:5784-92. doi: 10.1523/JNEUROSCI.4326-08.2009

103. Thompson AK, Cote RH, Sniffen JM, Brangaccio JA. Operant conditioning of the tibialis anterior motor evoked potential in people with and without chronic incomplete spinal cord injury. J Neurophysiol. (2018) 120:2745-60. doi: 10.1152/jn.00362.2018

104. Thompson AK, Favale BM, Velez J, Falivena P. Operant up-conditioning of the tibialis anterior motor-evoked potential in multiple sclerosis: feasibility case studies. Neural Plast. (2018) 2018:4725393. doi: 10.1155/2018/4725393

105. Kurtzke JF. Rating neurologic impairment in multiple sclerosis: an expanded disability status scale (EDSS). Neurology. (1983) 33:1444-52. doi: 10.1212/WNL.33.11.1444

106. Vicars SM, Miguel CF, Sobie JL. Assessing preference and reinforcer effectiveness in dogs. Behav Processes. (2014) 103:75-83. doi: 10.1016/j.beproc.2013.11.006

107. Lee MS, Yu CT, Martin TL, Martin GL. On the relation between reinforcer efficacy and preference. J Appl Behav Anal. (2010) 43:95-100. doi: 10.1901/jaba.2010.43-95

108. Klose KJ, Needham BM, Schmidt D, Broton JG, Green BA. An assessment of the contribution of electromyographic biofeedback as an adjunct therapy in the physical training of spinal cord injured persons. Arch Phys Med Rehabil. (1993) 74:453-6. doi: 10.1016/0003-9993(93)90103-H

109. Brucker BS, Bulaeva NV. Biofeedback effect on electromyography responses in patients with spinal cord injury. Arch Phys Med Rehabil. (1996) 77:133-7. doi: 10.1016/S0003-9993(96)90157-4
110. Kohlmeyer KM, Hill JP, Yarkony GM, Jaeger RJ. Electrical stimulation and biofeedback effect on recovery of tenodesis grasp: a controlled study. Arch Phys Med Rehabil. (1996) 77:702-6. doi: 10.1016/S0003-9993(96)90011-8

111. Petrofsky JS. The use of electromyogram biofeedback to reduce Trendelenburg gait. Eur J Appl Physiol. (2001) 85:491-5. doi: $10.1007 / \mathrm{s} 004210100466$

112. van Dijk H, Jannink MJ, Hermens HJ. Effect of augmented feedback on motor function of the affected upper extremity in rehabilitation patients: a systematic review of randomized controlled trials. J Rehabil Med. (2005) 37:202-11. doi: 10.1080/16501970510030165

113. Devillard X, Rimaud D, Roche F, Calmels P. Effects of training programs for spinal cord injury. Ann Readapt Med Phys. (2007) 50:490-8:480-9. doi: 10.1016/j.annrmp.2007.04.013

114. Sapienza CM, Wheeler K. Respiratory muscle strength training: functional outcomes versus plasticity. Semin Speech Lang. (2006) 27:236-44. doi: 10.1055/s-2006-955114

115. S. Van Houtte Vanlandewijck Y, Gosselink R. Respiratory muscle training in persons with spinal cord injury: a systematic review. Respir Med. (2006) 100:1886-95. doi: 10.1016/j.rmed.2006.02.029

116. Gregory CM, Bowden MG, Jayaraman A, Shah P, Behrman A, Kautz $\mathrm{SA}$, et al. Resistance training and locomotor recovery after incomplete spinal cord injury: a case series. Spinal Cord. (2007) 45:522-30. doi: $10.1038 /$ sj.sc.3102002

117. Hicks AL, Martin KA, Ditor DS, Latimer AE, Craven C, Bugaresti J, et al. Long-term exercise training in persons with spinal cord injury: effects on strength, arm ergometry performance and psychological well-being. Spinal Cord. (2003) 41:34-43. doi: 10.1038/sj.sc.3101389

118. Hartkopp A, Harridge SD, Mizuno M, Ratkevicius A, Quistorff B, Kjaer $\mathrm{M}$, et al. Effect of training on contractile and metabolic properties of wrist extensors in spinal cord-injured individuals. Muscle Nerve. (2003) 27:72-80. doi: 10.1002/mus. 10290

119. Dragert K, Zehr EP. Bilateral neuromuscular plasticity from unilateral training of the ankle dorsiflexors. Exp Brain Res. (2011) 208:217-27. doi: 10.1007/s00221-010-2472-3

120. Chen XY, Chen Y, Wang Y, Thompson A, Carp JS, Segal RL, et al. Reflex conditioning: a new strategy for improving motor function after spinal cord injury. Ann N Y Acad Sci. (1198) (2010) 1198:E12-21. doi: 10.1111/j.1749-6632.2010.05565.x

121. Trompetto C, Buccolieri A, Marinelli L, Abbruzzese G. Differential modulation of motor evoked potential and silent period by activation of intracortical inhibitory circuits. Clin Neurophysiol. (2001) 112:1822-7. doi: 10.1016/S1388-2457(01)00644-7

122. Ashby P, Reynolds C, Wennberg R, Lozano AM, Rothwell J. On the focal nature of inhibition and facilitation in the human motor cortex. Clin Neurophysiol. (1999) 110:550-5. doi: 10.1016/S1388-2457(98)00082-0

123. Inghilleri M, Berardelli A, Cruccu G, Manfredi M. Silent period evoked by transcranial stimulation of the human cortex and cervicomedullary junction. J Physiol. (1993) 466:521-34.

124. Knash ME, Kido A, Gorassini M, Chan KM, Stein RB. Electrical stimulation of the human common peroneal nerve elicits lasting facilitation of cortical motor-evoked potentials. Exp Brain Res. (2003) 153:366-77. doi: 10.1007/s00221-003-1628-9

125. Ziemann U, Rothwell JC, Ridding MC. Interaction between intracortical inhibition and facilitation in human motor cortex. J Physiol. (1996) 496 (Pt 3):873-81. doi: 10.1113/jphysiol.1996.sp021734

126. Di Lazzaro V, Ziemann U. The contribution of transcranial magnetic stimulation in the functional evaluation of microcircuits in human motor cortex. Front Neural Circuits. (2013) 7:18. doi: 10.3389/fncir.2013.00018

127. Nielsen JB, Tijssen MA, Hansen NL, Crone C, Petersen NT, Brown P, et al. Corticospinal transmission to leg motoneurones in human subjects with deficient glycinergic inhibition. J Physiol. (2002) 544(Pt 2):631-40. doi: 10.1113/jphysiol.22.024091

128. Boroojerdi B, Battaglia F, Muellbacher W, Cohen LG. Mechanisms influencing stimulus-response properties of the human corticospinal system. Clin Neurophysiol. (2001) 112:931-7. doi: 10.1016/S1388-2457(01)00523-5

129. Ziemann U, Lonnecker S, Steinhoff BJ, Paulus W. The effect of lorazepam on the motor cortical excitability in man. Exp Brain Res. (1996) 109:127-35. doi: 10.1007/BF00228633 
130. V. Di Lazzaro Oliviero A, Meglio M, Cioni B, Tamburrini G, Tonali P, Rothwell JC. Direct demonstration of the effect of lorazepam on the excitability of the human motor cortex. Clin Neurophysiol. (2000) 111:794-9. doi: 10.1016/S1388-2457(99)00314-4

131. Siebner HR, Dressnandt J, Auer C, Conrad B. Continuous intrathecal baclofen infusions induced a marked increase of the transcranially evoked silent period in a patient with generalized dystonia. Muscle Nerve. (1998) 21:1209-12. doi: 10.1002/(sici)1097-4598(199809)21:9<1209::aid-mus15>3.0.co;2-m

132. Tataroglu C, Genc A, Idiman E, Cakmur R, Idiman F. Cortical silent period and motor evoked potentials in patients with multiple sclerosis. Clin Neurol Neurosurg. (2003) 105:105-10. doi: 10.1016/S0303-8467(02)00127-0

133. McDonnell MN, Orekhov Y, Ziemann U. The role of GABA(B) receptors in intracortical inhibition in the human motor cortex. Exp Brain Res. (2006) 173:86-93. doi: 10.1007/s00221-006-0365-2

134. Werhahn KJ, Kunesch E, Noachtar S, Benecke R, Classen J. Differential effects on motorcortical inhibition induced by blockade of GABA uptake in humans. J Physiol. (1999) 517:591-7. doi: 10.1111/j.1469-7793.1999.0591t.x

135. Mrachacz-Kersting N, Kersting UG, de Brito Silva P, Makihara Y, ArendtNielsen L, Sinkjaer T, et al. Acquisition of a simple motor skill: taskdependent adaptation and long-term changes in the human soleus stretch reflex. J Neurophysiol. (2019) 122:435-46. doi: 10.1152/jn.00211.2019

136. Makihara Y, Segal RL, Wolpaw JR, Thompson AK. Operant conditioning of the soleus H-reflex does not induce long-term changes in the gastrocnemius H-reflexes and does not disturb normal locomotion in humans. $J$ Neurophysiol. (2014) 112:1439-46. doi: 10.1152/jn.00225.2014

137. Milinis K, Tennant A, Young CA, TONIC study group. Spasticity in multiple sclerosis: Associations with impairments and overall quality of life. Mult Scler Relat Disord. (2016) 5:34-9. doi: 10.1016/j.msard.2015.10.007

138. Nielsen J, Petersen N, Crone C. Changes in transmission across synapses of Ia afferents in spastic patients. Brain. (1995) 118:995-1004. doi: 10.1093/brain/118.4.995

139. Crone C, Nielsen J, Petersen N, Ballegaard M, Hultborn H. Disynaptic reciprocal inhibition of ankle extensors in spastic patients. Brain. (1994) 117:1161-8. doi: 10.1093/brain/117.5.1161

140. Morita H, Crone C, Christenhuis D, Petersen NT, Nielsen JB. Modulation of presynaptic inhibition and disynaptic reciprocal Ia inhibition during voluntary movement in spasticity. Brain. (2001) 124(Pt 4):826-37. doi: 10.1093/brain/124.4.826

141. Chen Y, Chen L, Wang Y, Wolpaw JR, Chen XY. Persistent beneficial impact of H-reflex conditioning in spinal cord-injured rats. J Neurophysiol. (2014) 112:2374-81. doi: 10.1152/jn.00422.2014

142. Chen Y, Chen L, Liu R, Wang Y, Chen XY, Wolpaw JR. Locomotor impact of beneficial or nonbeneficial H-reflex conditioning after spinal cord injury. J Neurophysiol. (2014) 111:1249-58. doi: 10.1152/jn.00756.2013

143. Thompson AK, Wolpaw JR. Operant conditioning of spinal reflexes to improve motor function after spinal cord injury. In: Fehlings MG, Vaccaro A, Boakye RS, Burns A, Di Tunno J, editors. Essentials of Spinal Cord Injury. New York, NY: Thieme Publishers. (2012). p. 545-557.

144. Chen Y, Chen XY, Jakeman LB, Chen L, Stokes BT, Wolpaw JR. Operant conditioning of H-reflex can correct a locomotor abnormality after spinal cord injury in rats. J Neurosci. (2006) 26:12537-43. doi: 10.1523/JNEUROSCI.2198-06.2006
145. Segal RL, Wolf SL. Operant conditioning of spinal stretch reflexes in patients with spinal cord injuries. Exp Neurol. (1994) 130:202-13. doi: 10.1006/exnr.1994.1199

146. Chalah MA, Kauv P, Creange A, Hodel J, Lefaucheur JP, Ayache SS. Neurophysiological, radiological and neuropsychological evaluation of fatigue in multiple sclerosis. Mult Scler Relat Disord. (2019) 28:145-52. doi: 10.1016/j.msard.2018.12.029

147. Dario A, Scamoni C, Picano M, Casagrande F, Tomei G. Pharmacological complications of the chronic baclofen infusion in the severe spinal spasticity. Personal experience and review of the literature. J Neurosurg Sci. (2004) 48:177-81.

148. Dario A, Tomei G. A benefit-risk assessment of baclofen in severe spinal spasticity. Drug Saf. (2004) 27:799-818. doi: 10.2165/00002018-200427110-00004

149. Shi J, Wu X, Chen Y. Study on Dalfampridine in the treatment of multiple sclerosis mobility disability: a meta-analysis. PLoS ONE. (2019) 14:e0222288. doi: 10.1371/journal.pone.0222288

150. Dunn J, Blight A. Dalfampridine: a brief review of its mechanism of action and efficacy as a treatment to improve walking in patients with multiple sclerosis. Curr Med Res Opin. (2011) 27:1415-23. doi: 10.1185/03007995.2011.583229

151. Applebee A, Goodman AD, Mayadev AS, Bethoux F, Goldman MD, Klingler $\mathrm{M}$, et al. Effects of Dalfampridine extended-release tablets on 6-minute walk distance in patients with multiple sclerosis: a post hoc analysis of a double-blind, placebo-controlled trial. Clin Ther. (2015) 37:2780-7. doi: 10.1016/j.clinthera.2015.10.014

152. Goodman AD, Brown TR, Krupp LB, Schapiro RT, Schwid SR, Cohen $\mathrm{R}$, et al. Sustained-release oral fampridine in multiple sclerosis: a randomised, double-blind, controlled trial. Lancet. (2009) 373:732-8. doi: 10.1016/S0140-6736(09)60442-6

153. Nicoletti CG, Monteleone F, Marfia GA, Usiello A, Buttari F, Centonze D, et al. Oral D-Aspartate enhances synaptic plasticity reserve in progressive multiple sclerosis. Mult Scler. (2020) 26:304-11. doi: $10.1177 / 1352458519828294$

154. Ferrucci R, Vergari M, Cogiamanian F, Bocci T, Ciocca M, Tomasini E, et al. Transcranial direct current stimulation (tDCS) for fatigue in multiple sclerosis. NeuroRehabilitation. (2014) 34:121-7. doi: 10.3233/NRE-13 1019

Conflict of Interest: AT holds several patents related to operant conditioning of spinal reflexes (US patent number 8862236,9138579 , and 9545515 ). These patents are not providing income in any form.

The remaining author declares that the research was conducted in the absence of any commercial or financial relationships that could be construed as a potential conflict of interest.

Copyright (C) 2020 Thompson and Sinkjor. This is an open-access article distributed under the terms of the Creative Commons Attribution License (CC BY). The use, distribution or reproduction in other forums is permitted, provided the original author(s) and the copyright owner(s) are credited and that the original publication in this journal is cited, in accordance with accepted academic practice. No use, distribution or reproduction is permitted which does not comply with these terms. 